I njury is the ninth most common cause of premature death worldwide and the third most common cause of years lived with disability. ${ }^{1}$ Many early deaths are related to traffic accidents: each year, crashes of road vehicles kill I.2 million people $(3242$ deaths/day) and injure or disable 20-50 million more. ${ }^{2}$ The Global Burden of Disease Study, ${ }^{1}$ conducted in the early I9gos, predicted that traffic-related injuries will become the third largest contributor to global death and disability by the year 2020.2

Most traffic-related deaths take place in low- and middle-income countries, mostly among young men $15-44$ years old, who are involved in $77 \%$ of all vehicular collisions. Pedestrians, cyclists, passengers on public transport and riders of motorized 2 -wheeled vehicles are those most commonly harmed. ${ }^{2}$ Affected families are impoverished by health care costs and loss of income. Even countries are debilitated: costs to low- and middle-income countries exceed US $\$ 65$ billion per year, ${ }^{2}$ which is more than the total amount received in these countries for development assistance.

In Child and Adolescent Injury Prevention: A Global Call to Action (http:/ /whqlibdoc.who.int/publications/2005

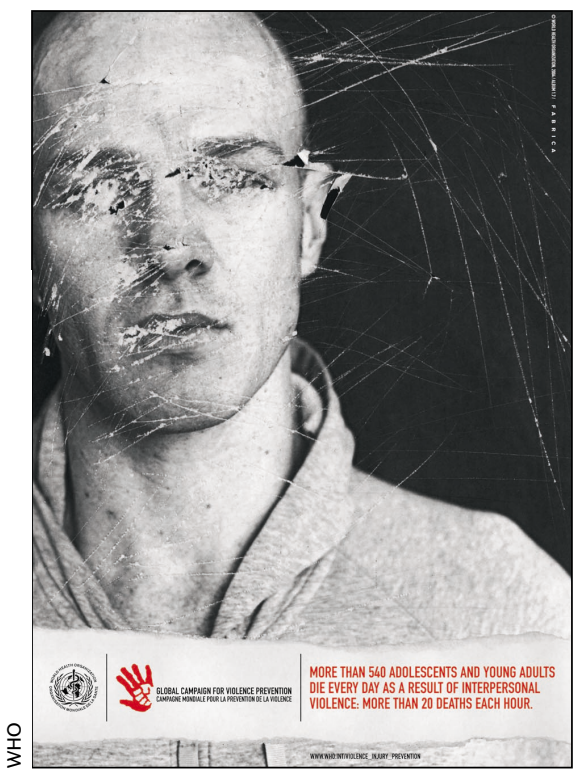

Two posters from the World Health Organization's Global Campaign for Violence Prevention. The text on this poster reads, "More than 540 adolescents and young adults die every day as a result of interpersonal violence: more than 20 deaths each hour."

1924I5934I5_eng.pdf), the World Health Organization (WHO) reported in 2005 that the most common causes of childhood injuries are road-related collisions, drownings, burns and falls - although child abuse and youth violence are also leading causes of death, especially deaths of older children. Almost a million children and adolescents

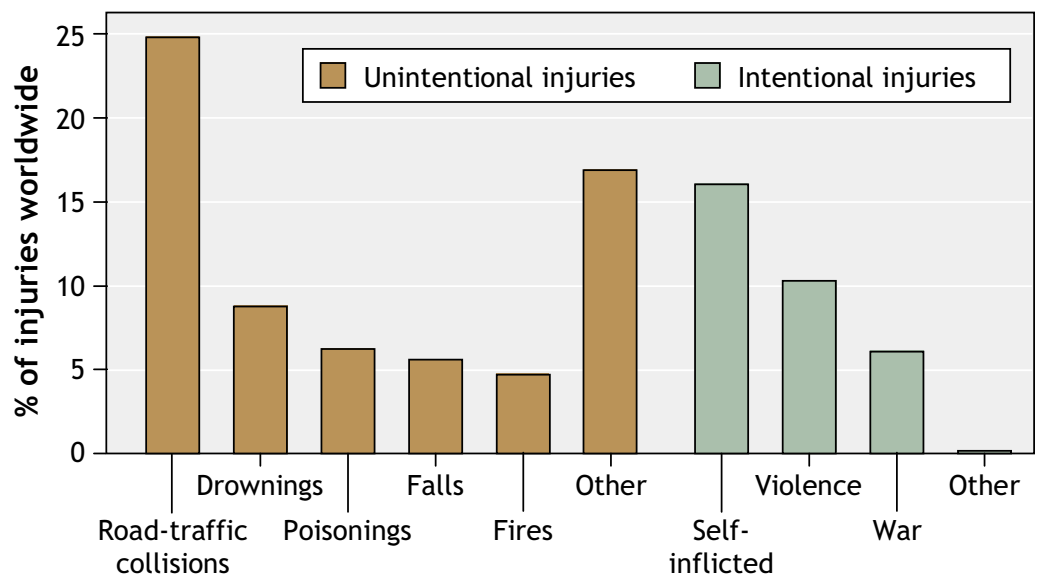

Causes of injury

Fig. 1: Causes of injuries worldwide. Source: World Health Organization. The Injury Chart Book: A Graphical Overview of the Global Burden of Injuries. Geneva: WHO; 2002. p. 19.

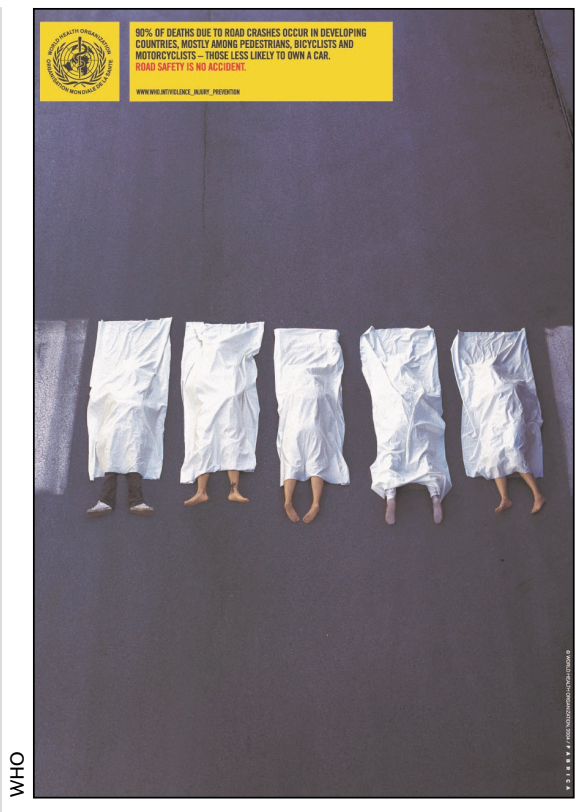

On this poster from WHO's Global Campaign for Violence Prevention, the text reads, "90\% of deaths due to road crashes occur in developing countries, mostly among pedestrians, bicyclists and motorcyclists - those less likely to own a car. Road safety is no accident." www.who.int/violence_injury_prevention

are injured each year by road-vehicle crashes; again, these injuries occur mostly (95\%) within low- and middleincome countries.

Just under a third of injuries worldwide $(32.8 \%)$ are recognizably intentional; half of these are self-inflicted and half result from interpersonal violence and war (Fig. I). Violence kills more than $\mathrm{I} .6$ million people worldwide each year, accounting for $14 \%$ of male deaths and $7 \%$ of female. Many more are injured and experience a range of physical, sexual, reproductive and mental health problems. ${ }^{3}$ Much of this violence occurs in the home; a recent WHO report found that the most common form of violence in women's lives is that from an intimate partner (Box I).

"Accidents" were formerly regarded as random events that were unavoidable. A better understanding of their nature has meant that injuries are now seen to be largely avoidable. As a result, injury prevention is now prominent on many public health agendas (Box 2).

Prevention efforts for traffic-related injuries centre on addressing individual 
and broader environmental factors that contribute to injuries. WHO recommends that countries develop a national strategy for improved transport safety that includes road engineering and transport planning agencies as well as health, education and law-enforcement bodies. ${ }^{2}$ It also calls for the specific allocation of financial and human resources and for the implementation of specific actions such as compulsory seat belts, child restraints and helmets; lowered speed limits; blood alcohol limits; and safe vehicle and road design (Box 3 ).

Current preventive approaches to violence received worldwide attention in 1996 when the World Health Assembly adopted a resolution declaring violence a leading problem in public health. ${ }^{3}$ This followed earlier calls to address the effect of violence against women and girls and world citizen safety (Box 4). As with injury, the management and understanding of violence is moving away from a "law-and-order" approach to a public health approach with emphasis on prevention and root-cause management. ${ }^{3}$ Primary prevention approaches include training for good parenting skills, improved urban infrastructure, social development programs for adolescents and children, and efforts to reduce the global drugs and arms trades. ${ }^{3}$

With raised awareness, better evidence as to what prevention strategies are effective, and community commitment to the problems of injury and violence, it is hoped that we can tackle the problem of largely preventable deaths.

\section{Sally Murray}

Editorial Fellow

CMAJ

\section{REFERENCES}

I. Murray CJ, Lopez AD, editors. The global burden of disease: a comprehensive assessment of mortality and disability from diseases, injuries and risk factors in 1990 and projected to 2020. Cambridge (MA): Harvard University Press; 1996.

2. World Health Organization. World report on road traffic injury prevention. Geneva: WHO; 2004. Available: www.who.int/violence_injury_prevention/en (accessed 2006 Jan 24).

3. World Health Organization. World report on violence and health. Geneva: WHO; 2002. Available: www.who.int/violence_injury_prevention/en (accessed 2006 Jan 24).

\section{Box 1: The Women's Health and Domestic Violence against Women Study*}

Of the more than 24000 women in 10 countries involved in the study,

- $13 \%-61 \%$ had experienced physical violence from an intimate partner

- $6 \%-59 \%$ had experienced sexual violence from an intimate partner

- $20 \%-75 \%$ experienced emotionally abusive or controlling behaviour from their intimate partner during the last 12 months

- Those who experienced sexual or physical violence reported poor mental and physical health, injuries and reproductive repercussions (e.g., abortion)

*The breadth of the ranges reflect varied experiences in the countries studied.

Source: World Health Organization. The Women's Health and Domestic Violence against Women Study. Geneva: WHO; 2005.

\section{Box 2: What's happening in injury prevention?}

- SafetyLit provides weekly updates about reports on unintentional injury, violence and self-harm from more than 2000 multidisciplinary journals, conference proceedings and reports from government agencies and organizations (www.safetylit.org)

- 8th World Conference on Injury Prevention and Safety Promotion, 2006 Apr 2-5, Durban, South Africa (www.safety2006.info/index.aspx)

- 1st European Conference on Injury Prevention and Safety Promotion: Challenges for a Safer Europe, 2006 June 25-27, Vienna, Austria

- International Society for Violence and Injury Prevention (www.isvip.org)

- Violence Prevention Alliance (www.who.int/violenceprevention/about/en)

\section{Box 3: World Health Organization fact file}

- Correct use of seat belts reduces the risk of death in a vehicular crash by $61 \%$

- Mandatory use of child restraints can reduce child deaths by $35 \%$

- Enforcement around the world of a law against drinking and driving could reduce alcohol-related crashes by $20 \%$

- Use of helmets reduces fatal and serious head injuries by up to $45 \%$

- For every $1-\mathrm{km} / \mathrm{h}$ reduction in average speed, there is a $2 \%$ reduction in the number of vehicular crashes

Source: World Health Organization. Ten facts about road safety. Geneva: WHO; 2005. Available: www.who.int/violence_injury_prevention/en (accessed 2006 Jan 24).

Box 4: Key declarations and recommendations for violence reduction

Targeting violence against women and girls

- United Nations Declaration on the Elimination of Violence Against Women, 1993

- International Conference on Population and Development, Cairo, 1994

- Fourth World Conference on Women, Beijing, 1995

Targeting world citizen safety

- Declaration of the World Summit for Social Development, 1995

- Melbourne Declaration, adopted at the Third International Conference on Injury Prevention and Control, 1996 